\title{
Taking personal initiative and communicating about ideas: What is important for the creative process and for idea creativity?
}

\author{
Carmen Binnewies \\ University of Konstanz, Konstanz, Germany \\ Sandra Ohly \\ University of Frankfurt, Frankfurt, Germany \\ Sabine Sonnentag \\ University of Konstanz, Konstanz, Germany
}

\begin{abstract}
Using multisource data, this study focused on the process aspect of creativity at work. A modification of Amabile's (1988) stage model of the creative process with the stages of problem identification, preparation, idea generation, and idea validation served as the basis for our study. We examined personal initiative and idea-related communication as two important factors for the creative process and for the degree of creativity of one specific idea an employee recently produced at work. In a sample of 52 nurses, we found that idea-related communication was positively related to engagement in the creative process but not to idea creativity. Personal initiative boosted engagement in the beginning of the creative process and was positively related to creativity as an outcome. Results suggest that idea-related communication is important for showing engagement in the creative process, whereas personal initiative is important in the beginning of the creative process and for idea creativity.
\end{abstract}

Creativity is a topic of growing interest as it encompasses the generation of new and potentially useful products, practices, services, or procedures

Correspondence should be addressed to Carmen Binnewies, Department of Psychology, Work \& Organizational Psychology Unit, University of Konstanz, PO Box D42, Konstanz 78457, Germany. E-mail: carmen.binnewies@uni-konstanz.de

We are grateful to Anneliese Westermann-Binnewies for help in data collection, especially for conducting the interviews. We would also like to thank Cornelia Niessen and Judith Volmer for comments on an earlier version of this article.

Konstanzer Online-Publikations-System (KOPS)

URL: http://www.ub.uni-konstanz.de/kops/volltexte/2008/5788/

URN: http://nbn-resolving.de/urn:nbn:de:bsz:352-opus-57889 
(Amabile, 1996; Shalley, Zhou, \& Oldham, 2004). Thereby, it is the precursor of an organization's innovation, effectiveness, and survival (Shalley et al., 2004). Creativity fosters an organization's competitive ability because it enables the organization to adjust to shifting environmental conditions and to take advantage of emerging opportunities (Oldham, 2003; Shalley et al., 2004).

Researchers primarily considered creativity as an outcome variable (Oldham \& Cummings, 1996; Shalley et al., 2004) and focused on identifying predictors of creativity such as personality and contextual factors (for an overview see Shalley et al., 2004). Little is known about the way individuals start, develop, and pursue creative behaviour at work, that is the process that precedes a creative outcome (Shalley et al., 2004). Research is needed to identify factors that play a role during this process (Rank, Pace, \& Frese, 2004).

Communication and personal initiative are two factors that have been shown to be beneficial for creativity as an outcome (Brodbeck, 2001; Frese, Teng, \& Wijnen, 1999; Keller, 2001). Thus, they might also play a role in the creative process. Personal initiative (PI) is one form of proactivity (Unsworth \& Parker, 2003) and defined as "a behaviour syndrome resulting in an individual's taking an active and self-starting approach to work and going beyond what is formally required in a given job" (Frese, Kring, Soose, \& Zempel, 1996, p. 38). Creative behaviour often requires a deviation from the standard way of working (Ford, 1996) and exploration of unfamiliar territory (Amabile et al., 2002). Therefore, PI should be important for continuing engagement in the creative process, for showing a high level of engagement in all stages of the creative process, and for idea creativity. Communicating with others about ideas is a task-related behaviour that enables individuals to share knowledge and expertise with others (Scott \& Bruce, 1994; Zhou \& George, 2001). Shared knowledge can be regarded as a useful resource for working on a creative solution. As a consequence, idea-related communication should be important for engagement in the creative process and for idea creativity. Research on the creative process in work settings is sparse and has examined the overall engagement in creative behaviour at work but does not differentiate between several subprocesses (Amabile et al., 2002; Gilson, Mathieu, Shalley, \& Ruddy, 2005; Gilson \& Shalley, 2004). Our study aims at providing a more detailed view of the creative process. We chose to look at PI and idea-related communication because they are behaviours proximal to creativity that can also be stimulated by the organization.

In our study, we asked study participants about a specific creative idea they had produced at work. By doing so, we differ from other approaches that ask about the amount of creative ideas or the general level of engagement in the creative process. A modification of Amabile's (1988, 1996) stage model of the creative process served as the basis for our study. By investigating PI and idea-related communication as predictors of the creative process and creativity as an outcome, our study goes beyond earlier 
research on creativity and examines in more detail how different factors are related to different stages of the creative process and to the quality of the idea. Figure 1 presents the main concepts and the hypothesized relationships to be tested in our study.

\section{CREATIVITY}

Creativity is consensually defined as the development of ideas or products that are both novel and potentially useful (Amabile, 1988; Shalley et al., 2004). Although creativity is a construct that is subjective and contextdependent by nature (Amabile, 1996), an agreement between individuals on what is creative is often achieved, especially if these individuals are familiar with the task domain (Amabile, 1996; Shalley et al., 2004). Thus, creativity can be measured as the consensual judgement of several observers (Amabile, 1996). Creativity is closely related to innovation. Whereas creativity is generally referred to as the generation of new ideas and is mostly studied at the individual level, innovation encompasses the introduction and implementation of new ideas and is mostly studied at the team or organizational level (Anderson, de Dreu, \& Nijstad, 2004; West, 2002). In this study, we focus exclusively on creativity.

\section{THE CREATIVE PROCESS}

Lubart (2001, p. 295) described the creative process as "the sequence of thoughts and actions that lead to a novel, adaptive production". By drawing on earlier models (Stein, 1953; Wallas, 1926), Amabile (1988) proposed a model of the creative process that includes the stages: (a) problem identification, (b) preparation, (c) idea generation, and (d) idea validation. The starting point for every creative behaviour is the emergence of a task or problem that offers the possibility to find a creative solution (Amabile, 1988). Amabile (1988, 1996) distinguishes between external versus internal problem identification. If an individual discovers a problem by himself or herself and decides to work on a creative solution for this problem, problem identification is regarded as internal. If an individual is presented with a problem where no routine solution is available, problem identification is referred to as external. This distinction is comparable to the distinction between internal versus external perceived locus of causality as pointed out by Deci and Ryan (1985b). ${ }^{1}$ Locus of causality refers to the perceived source of initiation and regulation of behaviour (Deci \& Ryan, 1985a). Amabile (1996) assumed that intrinsic motivation to work on the problem is lower under the condition of external compared to internal problem identification.

\footnotetext{
${ }^{1}$ We thank an anonymous reviewer for referring to Cognitive Evaluation Theory.
} 


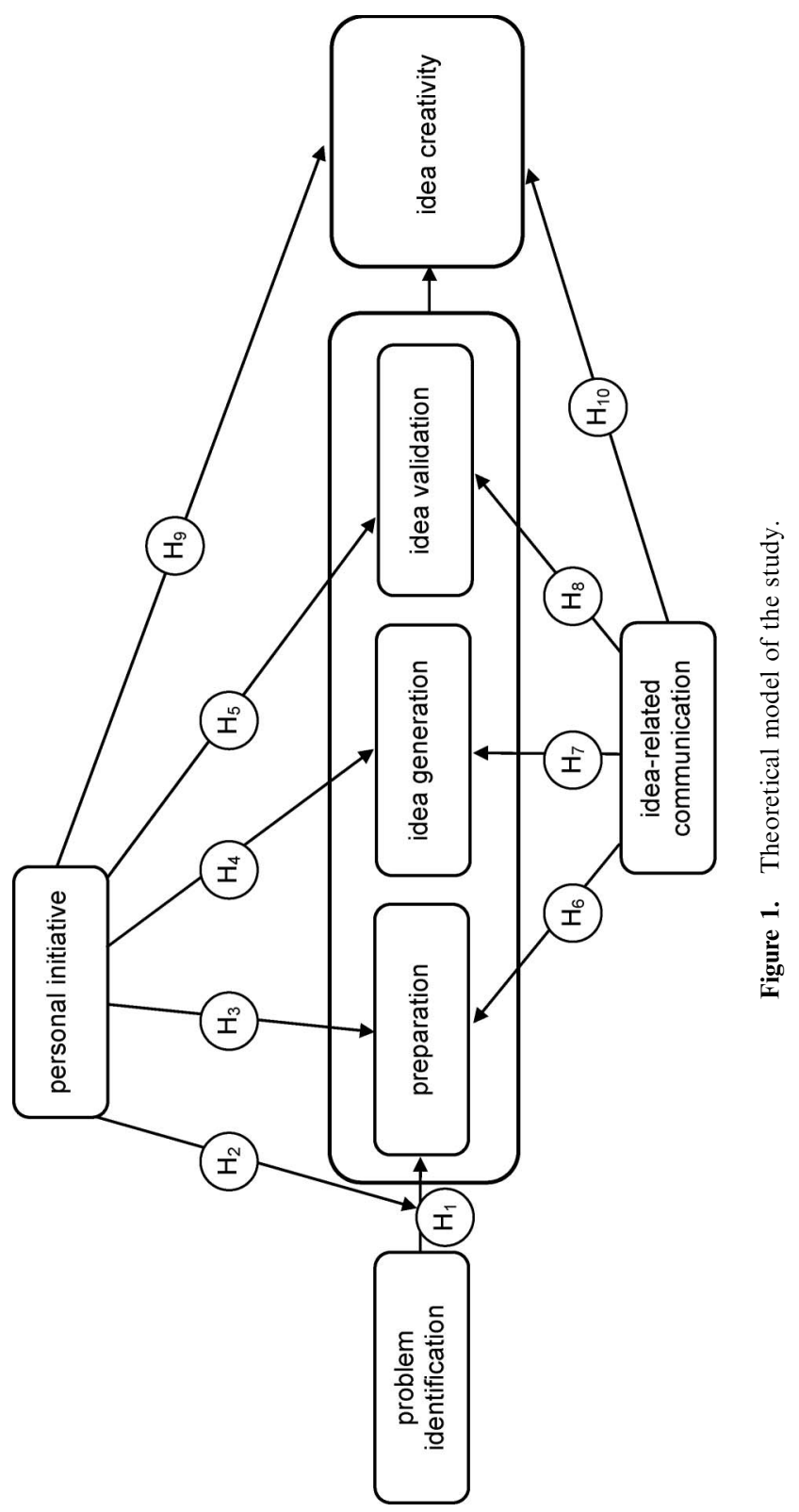


Preparation is the second stage in Amabile's $(1988,1996)$ model. In this stage, the individual gathers, builds up, or reactivates information and resources that could be relevant for generating potential solutions (Amabile, 1996). Preparation ranges from just "calling up relevant ideas" (Amabile, 1996, p. 95) to the acquisition of new, relevant skills or knowledge. The generation of ideas represents the third stage in the creative process. In this stage, the individual searches through available alternatives and explores relevant features of the environment. Consecutively, the ideas are tested against the relevant criteria for correctness or appropriateness in the fourth stage, named idea validation.

In a revision of the original model, Amabile (1996) included idea communication into the validation stage to emphasize that the idea has to be made explicit. However, we think that idea communication can also serve functions other than just the presentation of a final idea. Individuals might not only communicate about an idea that is already validated, but they might also communicate about a first vague idea in order to find out more about the task at hand and to use others' ideas to develop a solution. When faced with problems, individuals often find it useful to consult others to get advice (Clayton \& Birren, 1980; Staudinger \& Baltes, 1996). Thus, we view idea communication as a behaviour shown during the entire creativity process. To avoid misunderstandings with Amabile's (1996) conceptualization of idea communication, we name our concept idea-related communication.

Amabile $(1988,1996)$ assumes that the stages in the creative process represent a logical sequence. Although omission of single stages and recursions to previous stages are possible, the typical generation of ideas involves all stages in the presented order. Researchers suggested examining the creative process as a dynamic set of recursive subprocesses (Lubart, 2001). In our study, we consider the steps of the creative process as different subprocesses that precede a creative outcome. As problem identification is a specific locus of causality and not a behaviour, we regard problem identification as a precursory stage of the creative process.

Engagement in the creative processes can be conceptualized as a precondition for a creative outcome (Gilson \& Shalley, 2004). During the creative process, the creative idea is formed and refined. Although engagement in different subprocesses has been related to idea creativity (Lubart, 2001), research has not yet clarified how the creative process results in most creative ideas. One assumption is that a more creative idea results from more engagement in the subprocesses (Lubart, 2001). Alternatively, the sequence of engagement in the different subprocesses may be critical for more or less creative ideas. Otherwise, idea creativity may simply depend on an individual's knowledge and skills, but not on the extent of engagement (Lubart, 2001). The focus of our article is to identify predictors of engagement in the creative process and of idea creativity. We investigate the 
relationship between the creative process and idea creativity in an explorative way.

\section{Starting the creative process: The role of problem identification and personal initiative}

As noted earlier, a problem can either be identified internally or externally. In the case of internal problem identification, perceptions of the reasons for undertaking the tasks should be internal, and motivation to solve the encountered problem should be higher compared to external problem identification (Amabile, 1996). In accordance with Deci and Ryan (1985b), internal problem identification raises feelings of autonomy that in turn foster an individual's motivation to find a creative solution. Thus, internal problem identification acts as the driver to show high engagement in the creative process. In case of external problem identification, the individual is confronted with a problem, but an internal driver to solve this problem is missing. Engagement in the creative process after problem identification should be expressed by engagement in the preparation stage (Amabile, 1996). Therefore, we state:

Hypothesis 1: Internal problem identification is positively related to preparation.

However, engagement in the preparation stage is not necessarily low after external problem identification. We propose that PI moderates the relationship between locus of problem identification and engagement in the preparation stage. PI is characterized by behaviour consistent with organizational goals, a long-term orientation, being goal-directed and action-oriented, staying persistent in the face of barriers and set-backs, and being self-starting and proactive (Frese \& Fay, 2001). Because of its active, self-starting nature, we expect PI to be particularly important to carry on with a given problem.

An externally presented problem is associated with a lower internal motivation and can be seen as a barrier that must be overcome. Because PI implies actively attacking problems and being persistent in the face of barriers (Frese, Fay, Hilburger, Leng, \& Tag, 1997), PI should make it more likely to continue working on a creative solution, which means to engage in the preparation subprocess. Thus, we state:

Hypothesis 2: Personal initiative moderates the relationship between problem identification and preparation. Compared to persons with a lower degree of personal initiative, persons with a higher degree of personal initiative show more engagement in the preparation stage if the problem is externally identified. 


\section{Engagement in the creative process and its relationships with personal initiative}

We assume that PI is related to engagement in the three subprocesses of preparation, idea generation, and idea validation. During preparation, an individual gathers new information and builds up new resources in order to be equipped for generating new ideas. As PI involves actively scanning the environment for information (Frese \& Fay, 2001), PI should generally foster engagement in the preparation stage. Furthermore, PI comprises maintaining working on a task in spite of frustration (Frese \& Fay, 2001). PI should make it more likely to be persistent under difficult conditions that are usually associated with a creative problem. Consequently, we hypothesize PI to be positively related to preparation.

During idea generation, an individual develops different solutions for the problem at hand. According to Frese and Fay (2001), PI involves having backup plans for various situations. Therefore, we expect individuals high in PI to actively run through and develop various ideas. Thus, PI should be beneficial for the subprocess of idea generation. In fact, Frese et al. (1999) found PI to be positively related to having more ideas.

Idea validation encompasses deliberation about different ideas and comparison of their advantages and disadvantages. PI involves the consideration of potential problem areas and opportunities (Frese \& Fay, 2001). This behaviour should bring about a mental representation of the actions that are most successful. Therefore, PI should benefit idea validation. In sum, we assume:

Hypothesis 3: Personal initiative is positively related to preparation.

Hypothesis 4: Personal initiative is positively related to idea generation.

Hypothesis 5: Personal initiative is positively related to idea validation.

\section{Engagement in the creative process and its relationship with idea-related communication}

Idea-related communication has been emphasized as an important factor for the creative process and for creativity as an outcome (Amabile, 1988, 1996; Perry-Smith \& Shalley, 2003). Communicating with others about an idea may enhance an individual's motivation to engage in the creative subprocesses. First, by communicating about an idea, the individual "announces" that he or she is working on a creative solution for a specific problem and thus commits him- or herself to working on this problem. Public goal commitment has a strong effect on goal pursuit and goal achievement (Hollenbeck, Williams, \& Klein, 1989; Pallak \& Sullivan, 1979). Second, during idea-related communication, an individual may also 
experience encouragement and emotional support to continue working on a creative solution. Encouragement and support signal that creative ideas are valued and accepted by others and thus raise an individual's motivation to continue engagement in the creative process.

Moreover, by idea-related communication, an individual shares his or her knowledge with others. Others may bring in their own expertise and knowledge (Scott \& Bruce, 1994; Zhou \& George, 2001). Thereby, the individual may be provided with new knowledge and insights. These resources can prompt an individual to redefine the problem and to pursue a different approach to solve the problem. The input may in turn stimulate the individual to gather further information, that is to engage in the preparation stage. Furthermore, knowledge and ideas from others can directly result in the generation of new ideas. The individual can benefit from new perspectives by combining them with already known information (Mumford, Whetzel, \& Reiter-Palmon, 1997) and thus idea generation is raised. Moreover, idea-related communication can also provide the individual with an evaluation of the ideas' novelty and usefulness (PerrySmith \& Shalley, 2003). Therefore, idea-related communication should make it more likely that an individual (re-)validates his or her ideas. In sum, we assume:

Hypothesis 6: Idea-related communication is positively related to preparation.

Hypothesis 7: Idea-related communication is positively related to idea generation.

Hypothesis 8: Idea-related communication is positively related to idea validation.

\section{Idea creativity and its relationships with idea-related communication and personal initiative}

Creative behaviour often requires a deviation from the standard way of working (Ford, 1996) and an exploration of unfamiliar territory (Amabile et al., 2002). Because PI involves going beyond what is formally required (Frese \& Fay, 2001), it is expected to be related to the development of new ideas. In addition, PI involves being oriented towards organizational goals (Frese \& Fay, 2001). Therefore, it is likely that the ideas produced will also be valuable. Thus, the two characteristics of a creative outcome should be more likely achieved by a person showing high PI. Moreover, PI implies persistence when obstacles occur. To arrive at a creative outcome, it is beneficial to show continuous engagement in the creative process, and PI will foster this engagement. Consequently, we assume that persons high in PI will achieve outcomes that are more creative. Indeed, PI is positively 
related to having ideas (Frese et al., 1999) and to self-rated creativity (Ohly, Sonnentag, \& Pluntke, 2006). Consequently, we suppose:

Hypothesis 9: Personal initiative is positively related to idea creativity.

We also expect idea-related communication to be related to the creative outcome. Communicating about one's idea should enable an individual to share knowledge with others. If an individual communicates with others, he or she probably gets an evaluation of the thoughts and ideas and learns about what kind and parts of ideas are valued by others (Leenders, van Englen, \& Kratzer, 2003). Thereby, the individual can get some orientation about what others would probably see as new and useful. This information should enable the individual to adapt to common expectations, and to develop an idea that is viewed as creative by others. Furthermore, idea-related communication requires clarification of an idea before it can be articulated. One has to translate the product of thought into language that the communication partner can understand. During articulation, some obscurities or inconsistencies may become evident that have not been realized before (Chi, de Leeuw, Chiu, \& LaVancher, 1994). Thus, the input from the communication partner may improve the idea. Furthermore, a self-reflective process that may occur during idea-related communication may lead to the idea's improvement. In the end, this should lead to a more elaborated, more creative idea. Research on teams provided some empirical evidence that communication is positively related to performance in general, including evaluations of team creativity (Hyatt \& Ruddy, 1997; Keller, 2001). In sum, we state:

Hypothesis 10: Idea-related communication is positively related to idea creativity.

\section{METHOD}

\section{Overview}

To minimize common method bias (Podsakoff, MacKenzie, Jeong-Yeon, \& Podsakoff, 2003), we collected three different types of data. First, as part of a larger study, participants responded to a questionnaire that included a self-report measure of personal initiative. In this questionnaire, we also assessed demographic data. Second, participants were interviewed about an idea they had had at work, and about the creative processes. The interviews were conducted by a psychologist who did not know about the hypotheses, to avoid expectancy effects. Finally, the ideas participants reported in the interview were rated by three subject-matter experts according to the Consensual Assessment Technique (Amabile, 1996). To minimize biases in terms of social desirability or implicit theories about research hypotheses, we 
made no reference to creativity throughout the process of data collection. Instead, the study was announced to examine "novel ideas at work".

\section{Sample}

We chose nursing staff as the sample for this study because here creativity should occur on the basis of both internal and external problem identification. Prior to data collection, we conducted interviews with experts in the field that revealed that having novel and useful ideas is common among nurses and important for organizational functioning as well. Furthermore, creativity has already been studied in nurses (Zhou, 2003). Examples from our study for highly creative ideas are the introduction of eating in small groups for patients who had problems eating their meals alone, the introduction of ward rounds for nurses similar to the ward rounds that are carried out by doctors, or new ways of putting patients to bed using new material. Less creative ideas were, for example, small changes in the workflow or in the documentation system.

Our sample included 52 individuals $(76.9 \%$ female). Among the participants were $42(80.8 \%)$ registered nurses and $10(19.2 \%)$ trainee nurses in the final stage of education. Mean age was 34.5 years $(S D=10.9$ years) and mean job experience was 12.4 years ( $S D=10$ years). Almost half of the participants $(44.2 \%)$ held a leadership position. Participants worked in different areas of nursing, mainly in nursing the sick and the elderly. At the time of data collection, $28.8 \%$ of the participants attended a course of advanced vocational training. Recruitment of study participants took place in training institutes where current and former course participants were asked to take part in the study. Furthermore, study participants were requested to ask colleagues to participate in our study. Persons who agreed to participate first filled out the questionnaire, and were afterwards asked to volunteer for an interview. Approximately one-third of the persons who filled out a questionnaire volunteered for the interview. We checked whether there were systematic differences between participants who volunteered for the interview and participants who did not. Results indicated that interview participants were more likely to be registered nurses, more frequently attended advanced vocational training, and worked less frequently during the night. Questionnaire data and ratings of idea-related communication were not available for five and two study participants, respectively. Therefore, listwise deletion led to $N=45$ for some of the analyses.

\section{Interview procedure}

For assessing the creative process, we developed a standardized interview. Interviews are useful to measure constructs that cannot be captured in 
self-reported questionnaire measures (Bartholomew, Henderson, \& Marcia, 2000) because they are not accessible to participants' conscious awareness. Interviewing individuals about their thoughts and actions during the creative process makes it easier for them to give a good account of what happened. The interview consisted of three parts. The first part was a "warming up phase": Participants were familiarized with standardized questioning, were assured of anonymous handling of the data, and gave consent for the tape-recording of the interview.

The second part of the interview aimed at asking participants to report and describe a new idea at work they had had within the last month. The interviewer read a short introduction to explain the concept and to give some examples. If participants indicated they had had more than one idea they were instructed to report the idea they thought was the best. The interviewer used two standardized prompts if a participant stopped describing the idea or just gave a short answer ("What exactly was your new idea?"; "What exactly did you do or did you plan to do?").

In the third part of the interview, participants rated their engagement in the creative subprocesses. The interview manual was designed like a questionnaire and the participant could read the items and see the rating scales (see description later) while the interviewer read them out loud. Questions about the locus of problem identification were asked first, followed by questions about the preparation, idea generation, and idea validation subprocesses, and finally the level of idea-related communication. The interview was finished by debriefing and thanking participants for their cooperation. On average the interview length was $8: 43 \mathrm{~min}(S D=1: 51$; ranging from 5:43 $\mathrm{min}$ to $12: 15 \mathrm{~min}$ ).

\section{Measures}

Personal initiative was measured in the questionnaire with a seven-item scale capturing the general tendency to show personal initiative at work (Frese et al., 1997). Answers were given on a 5-point scale ranging from $1=$ "do not agree" to $5=$ "totally agree". A sample item was "I actively attack problems". Cronbach's alpha was .84 .

Idea creativity was the averaged expert rating of the ideas reported in the interview. Three experts (two female, one male) in the field of nursing rated the ideas. The experts were all registered nurses who had attended vocational training to become teachers of nursing, and their working experience as a teacher of nursing ranged between 10 and 30 years.

The procedure for rating the creativity of the reported ideas was similar to the procedure used by Zhou (1998; Zhou \& Oldham, 2001). The experts received a transcript of the participants' statements about the new idea and guidelines including a definition of creativity and some examples. 
Raters were instructed to randomly choose 15 examples and read them, in order to familiarize themselves with the range of reported ideas. Afterwards they rated each idea with respect to its novelty, its usefulness, and its overall creativity (defined as novelty and usefulness). The ratings of novelty and usefulness were made to ensure that both dimensions were observed when undertaking the overall rating of creativity. Following Zhou and Oldham (2001), only the rating of overall creativity was used as a measure of the creative outcome. Overall creativity was rated on a 10-point scale ranging from $1=$ "not creative at all" to $10=$ "extremely creative". The raters were asked to take into account if the ideas were reported by trainee nurses or by registered nurses. This was done to ensure that the evaluation of creativity was made in consideration of the participants' work context and experience (Amabile, 1996). Knowledge and experience have been shown as crucial determinants of creativity (Amabile, 1996; Sternberg, O'Hara, \& Lubart, 1997). Because we were not interested in studying the relationships between idea creativity and experience, we controlled for these variables by giving raters the information if the reported idea was from a trainee or from a registered nurse.

To test interrater reliability, we computed an intraclass correlation coefficient (ICC) with the factor rater as fixed. The ICC was .93, indicating an excellent level of interrater reliability and thus confirming the internal validity of our measure.

Idea-related communication was assessed with three self-developed interview items measuring the extent to which individuals communicated with others about the idea they reported in the interview. Thus, the items target an individual's report of the actual behaviour during the creative process. The three items were "I presented my idea to my colleagues or supervisor", "I told my colleagues or supervisor about my new idea", and "I informed my colleagues or supervisor how I could address the task in a different way." Cronbach's alpha was .87.

Internal or external problem identification and the engagement in the preparation, idea generation, and idea validation subprocesses were assessed by self-reports during the interview. After participants had described their ideas, they had to answer several specific questions about what they did during the creative process. All answers were given on a 5-point scale ranging from $1=$ "do not agree" to $5=$ "totally agree".

Problem identification was measured with two items that asked if the idea was internally or externally identified. The two items were "I came up with the idea myself" and "The situation required a new idea" (recoded). A high score on this scale means that the problem was more internally identified. The correlation between both items was $r=.54$. Preparation was measured with the three items "I gathered more information about the task at hand", "I acquired new knowledge about the task at hand", and "I deliberately 
prepared myself to come up with a new idea." Cronbach's alpha was .89 . Idea generation was measured with the three items "I developed different alternatives to approach this task", "I searched for different options for a new approach", and "I accumulated different options of how I can approach the task differently." Cronbach's alpha was .96. Idea validation was assessed with the three items "I thought about all advantages and disadvantages of each alternative to approach the task", "I intensely deliberated about which option would be the best to implement my idea", and "I balanced different options of how to approach the task differently and ultimately decided in favour of one." Cronbach's alpha was .97.

To examine the factor structure of all newly developed scales used in the interview, we conducted an exploratory factor analysis using oblimin rotation. Items from the scales idea-related communication, problem identification, preparation, idea generation, and idea validation were included in the analysis. In accordance with the assumed structure, five factors with Eigenvalues greater than 1 emerged. All items loaded on the designated scales. ${ }^{2}$

Control variables were additionally measured to account for possible influences of third variables. These control variables included demographic data (age, gender, education), specific questions about job-related education (length of job experience, completed advanced training), status (leadership position), and data on shift work and night work.

\section{RESULTS}

Zero-order correlations between all study variables and potential control variables (displayed in Table 1) revealed that having a leadership position was related to engagement in most stages of the creative process and to idea creativity. Therefore, when testing the hypotheses, we controlled for leadership position. Other potential control variables were not related to any stage of the creative process or to idea creativity when controlling for leadership position, and were therefore excluded from analyses.

Table 1 above the diagonal shows the partial correlation matrix between study variables, controlling for leadership position. Preparation was marginally related to idea generation $(r=.26)$. Idea generation in turn was significantly related to idea validation $(r=.43)$. Moreover, preparation was also positively $(r=.29)$ related to idea creativity.

To test our hypotheses, we conducted hierarchical regression analyses. In the first regression model, we predicted preparation and tested Hypothesis 1 (relationship between internal problem identification and preparation), Hypothesis 2 (moderating effect of PI on the relation between problem

\footnotetext{
${ }^{2} \mathrm{An}$ additional table presenting factor loadings and total variance explained is available from the first author on request.
} 
identification and preparation), Hypothesis 3 (relationship between PI and preparation), and Hypothesis 6 (the relationship between idea-related communication and preparation). Leadership position as a control variable was entered in the first step; problem identification, PI, and ideacommunication were entered in the second step; and the interaction term of PI and problem identification was entered in the third step. Table 2 shows the results of the regression analysis. In Step 2, idea-related communication significantly predicted preparation $(B=.39)$, but neither internal problem

TABLE 1

Means, standard deviations, and intercorrelations of main study variables

\begin{tabular}{lccccccccccc}
\hline & $M$ & $S D$ & 1 & 2 & 3 & 4 & 5 & 6 & 7 & 8 \\
\hline 1 Leadership & 1.44 & 0.50 & & - & - & - & - & - & - & - \\
$\begin{array}{c}\text { position } \\
\text { a }\end{array}$ & 4.03 & 0.78 & .09 & & .15 & .07 & .17 & $.26^{+}$ & .07 & .19 \\
$2 \begin{array}{l}\text { Internal problem } \\
\quad \text { identification }\end{array}$ & & & & & & & & & & \\
3 Preparation & 3.19 & 0.97 & $.46^{* *}$ & .17 & & $.26^{+}$ & -.10 & $.38^{* *}$ & -.10 & $.29^{*}$ \\
4 Idea generation & 2.99 & 0.99 & $.27^{+}$ & .09 & $.35^{*}$ & & $.43^{* *}$ & $.30^{*}$ & .16 & .11 \\
5 Idea validation & 3.26 & 0.97 & $.34^{*}$ & .19 & .07 & $.48^{* *}$ & & $.31^{*}$ & .11 & .07 \\
6 Idea communication & 4.02 & 0.50 & .15 & $.27^{+}$ & $.40^{* *}$ & $.32^{*}$ & $.31^{*}$ & & .21 & $.31^{*}$ \\
7 Personal initiative & 3.82 & 0.62 & $.31^{*}$ & .10 & .12 & $.25^{+}$ & .24 & .25 & & $.40^{* *}$ \\
8 Idea creativity & 6.32 & 1.86 & $.29^{*}$ & .20 & $.38^{* *}$ & .18 & .16 & $.34^{*}$ & $.47^{* *}$ & \\
\hline
\end{tabular}

Correlations below the diagonal are zero-order correlations. Correlations above the diagonal are partial correlations, controlling for leadership position. $N$ varies between $N=45$ and $N=52$ due to missing values.

${ }^{\mathrm{a}} 1=$ no leadership position, $2=$ leadership position. ${ }^{+} p<.10,{ }^{*} p<.05,{ }^{* *} p<.01$.

TABLE 2

Hierarchical regression analysis predicting preparation

\begin{tabular}{llccccc}
\hline & & Beta & $\Delta R^{2}$ & $\Delta F$ & $R^{2}$ & $F$ \\
\hline Step 1 & Leadership position & $.41^{* *}$ & & & .17 & $8.71^{* *}$ \\
Step 2 & Leadership position & $.39^{* *}$ & .14 & $2.75^{+}$ & .31 & $4.51^{* *}$ \\
& Problem identification & .10 & & & & \\
& Personal initiative (PI) & -.18 & & & & \\
& Idea-related communication & $.35^{*}$ & & & & \\
Step 3 & Leadership position & $.30^{*}$ & .10 & $6.67^{*}$ & .41 & $5.45^{* *}$ \\
& Problem identification (problem ID) & .05 & & & & \\
& Personal initiative (PI) & -.20 & & & & \\
& Idea-related communication & $.36^{*}$ & & & & \\
& PI $\times$ Problem ID & $-.35^{*}$ & & & & \\
\hline
\end{tabular}

$n=45 .{ }^{+} p<.10, * p<.05, * * p<.01$. 
identification nor PI were significant predictors. The more individuals communicated about their idea, the more they engaged in the stage preparation. Thus, we found support for Hypothesis 6, but not for Hypotheses 1 and 3. The interaction term entered in Step 3 was significant. The interaction effect can be seen in Figure 2. According to the procedure described by Aiken and West (1991), we tested the simple slopes for the relationship between problem identification and preparation under conditions of high and low personal initiative. For individuals high on PI, problem identification was unrelated to preparation, $B=-.02, t=-0.08$, $n s$. These individuals started with preparation irrespective of whether they identified the problem themselves or whether the situation pointed to a potential problem. For individuals with low PI, problem identification was positively related to preparation, $B=.50, t=2.45, p<.05$. Individuals with low PI prepared more for problem solution the more they identified the problem internally. Consequently, Hypothesis 2 was supported.

In the second regression model, we predicted idea generation to test for Hypothesis 4 (PI is positively related to idea generation) and Hypothesis 7 (idea-related communication is positively related to idea generation). Results can be seen in Table 3. Idea-related communication was positively

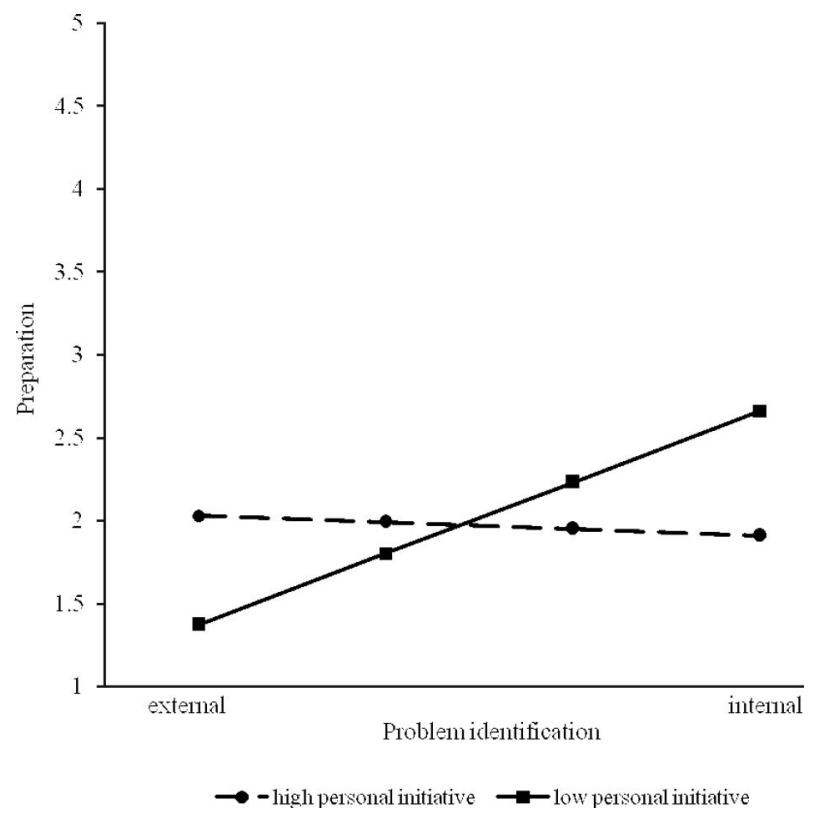

Figure 2. The interaction effect of personal initiative and internal problem identification on preparation. 
related to idea generation $(B=.30)$, but PI was not. Therefore, we found support for Hypothesis 7, but not for Hypothesis 4.

In the third model, we regressed idea validation on personal initiative and idea-related communication to test for Hypothesis 5 (PI is positively related to idea validation) and Hypothesis 8 (idea-related communication is positively related to idea validation). Results are shown in Table 4. Idearelated communication was marginally positively related to idea generation $(B=.25)$, but PI was unrelated to idea generation. Thus, Hypothesis 8 was supported, but Hypothesis 5 was not.

To test our assumption that PI and idea-related communication are positively related to idea creativity (Hypotheses 9 and 10), we conducted an analysis regressing idea creativity on idea-related communication and on PI. Results are shown in Table 5. PI significantly predicted idea creativity

TABLE 3

Hierarchical regression analysis predicting idea generation

\begin{tabular}{lllllll}
\hline & & Beta & $\Delta R^{2}$ & $\Delta F$ & $R^{2}$ & $F$ \\
\hline Step 1 & Leadership position & $.30^{*}$ & & & .09 & $4.29^{*}$ \\
Step 2 & Leadership position & $.25^{+}$ & .10 & $2.47^{+}$ & .19 & $3.17^{* *}$ \\
& Personal initiative & .05 & & & & \\
& Idea-related communication & $.30^{*}$ & & & & \\
\hline
\end{tabular}

$n=45 .{ }^{+} p<.10,{ }^{*} p<.05,{ }^{* *} p<.01$.

TABLE 4

Hierarchical regression analysis predicting idea validation

\begin{tabular}{lllllll}
\hline & & Beta & $\Delta R^{2}$ & $\Delta F$ & $R^{2}$ & $F$ \\
\hline Step 1 & Leadership position & $.36^{*}$ & & & .13 & $6.35^{*}$ \\
Step 2 & Leadership position & .28 & .09 & $2.60^{+}$ & .23 & $4.01^{*}$ \\
& Personal initiative & .15 & & & & \\
& Idea-related communication & $.25^{+}$ & & & & \\
\hline
\end{tabular}

$n=45 .{ }^{+} p<.10,{ }^{*} p<.05, * * p<.01$.

TABLE 5

Hierarchical regression analysis predicting idea creativity

\begin{tabular}{lllllll}
\hline & & Beta & $\Delta R^{2}$ & $\Delta F$ & $R^{2}$ & $F$ \\
\hline Step 1 & Leadership position & $.33^{*}$ & & & .11 & $5.10^{*}$ \\
Step 2 & Leadership position & .20 & .19 & $5.62^{* *}$ & .30 & $5.81^{* *}$ \\
& Personal initiative & $.36^{*}$ & & & & \\
& Idea-related communication & .20 & & & & \\
\hline
\end{tabular}

$n=45 . * p<.05, * * p<.01$. 
$(B=.36)$, but idea-related communication was not a significant predictor. Therefore, Hypothesis 9 was supported, whereas Hypothesis 10 was not.

\section{Additional analysis}

In an exploratory analysis, we tested if the creative subprocesses are related to idea creativity. Therefore, we predicted idea creativity by the creative subprocesses of preparation, idea generation, and idea validation. The regression model was significant, $F=3.06, p<.05$, explaining $16 \%$ of the variance in idea creativity. Preparation $(B=.37)$ was a significant predictor of idea creativity, whereas idea generation $(B=-.02)$ and idea validation $(B=.15)$ were unrelated to idea creativity.

Furthermore, we were interested in whether the relationships of personal initiative (PI) and idea-related communication with idea-creativity were mediated by engagement in the creative process. From tests of Hypotheses 2 , 3 , and 4, however, we know that personal initiative is not related to the creative subprocesses. Thus, this predictor is not related to the mediators, a necessary condition for mediation according to Baron and Kenny (1986). From testing Hypothesis 8, we know that idea-related communication is unrelated to idea creativity (also a necessary condition according to Baron \& Kenny, 1986). Therefore, there is no support for the assumption that the creative subprocesses of preparation, idea generation, and idea validation mediate the relationships of personal initiative and idea-related communication with idea creativity. ${ }^{3}$

\section{DISCUSSION}

Our study examined the relationships between personal initiative (PI) and idea-related communication with engagement in the creative process and with idea creativity. PI was found to be important for creativity in two ways. First, in the beginning of the creative process, PI moderated the relationship between problem identification and preparation. For individuals with high PI, the way of problem identification, internal versus external, did not matter with respect to engagement in the preparation stage. For individuals with low PI, engagement in the preparation stage was positively related to internal problem identification. Second, PI was positively related to idea creativity. Contrary to our expectations, PI was not related to engagement in the subprocesses of preparation, idea generation, and idea validation. Idea-related communication was positively related to preparation, idea generation, and idea validation of the creative process, but was unrelated to idea creativity.

\footnotetext{
${ }^{3}$ Additional analyses and tables concerning mediation analyses are available from the first author on request.
} 
In contrast to our expectation, we did not find support for the assumption that individuals engage more in the beginning of the creative process, that is in the preparation stage when the problem was more internally identified. One explanation is that in our sample the average level of internal problem identification was very high (mean $=4.03$ on a 5 -point scale). Thus, the range of different levels of problem identification was restrained, making it more difficult to detect the proposed relationship between internal problem identification and preparation. Another explanation is that the proposed relationship does not hold for all individuals but is moderated by other variables, such as PI. In the beginning of the creative process, individuals with high PI seem to actively attack a problem, and thus seem to be willing to face and overcome the problem and corresponding barriers irrespective of whether the problem is internally or externally identified. A high degree of personal initiative makes it more likely that a person shows a high level of engagement in the beginning of the creative process, namely in preparation, even if the problem was presented externally. Therefore, PI seems to serve as a motivational promoter at this stage and makes it more likely that an individual engages in working on a creative solution.

Furthermore, PI was positively related to idea creativity. It is important to keep in mind that our measure of idea creativity refers to the quality of a creative idea. It does not measure whether an individual generates a creative idea at all or how often an individual generates a new idea, but it measures the degree of an idea's creativity. PI was not related to engagement in the creative process. Individuals high in PI are goal oriented and strive to achieve a creative outcome but do not engage more in the preceding creative process. More engagement in the creative subprocesses also implies spending more time working on the creative solution. Because persons high in PI are goal oriented and therefore focus on arriving at a creative outcome, they might not be willing to spend too much time in the preceding creative process, but might want to put the idea into practice. Persons high in PI might also achieve a higher idea creativity by identifying more important problem areas. Because PI is related to idea creativity but not to the creative process, it is a question for future research to examine how individuals high in PI achieve a creative outcome.

We found support for our hypothesis that idea-related communication is associated with engagement in the three creative subprocesses of preparation, idea generation, and idea validation. Through idea-related communication an individual probably gets access to feedback from others, can access their knowledge and expertise, and gain new insights. This new perspective and knowledge can stimulate engagement in the creative subprocesses. New ways to address the problem at hand can be traced, explored, and validated.

Contrary to our hypothesis, idea-related communication was not a predictor of idea creativity. While the correlation between idea-related 
communication and idea creativity reached statistical significance (see Table 2), idea-related communication did not predict idea creativity when PI was entered in the regression equation at the same time. Previous research on the relationship between communication and performance produced mixed empirical evidence (Brodbeck, 2001; Leenders et al., 2003). Therefore, moderators have been suggested and studied. Standardization of work procedures is one moderator that might play a role in the context of our study: It has been shown that communication is less or not at all beneficial if the standardization of work procedures is high (Brodbeck, 2001) and undoubtedly, in our sample of nurses, standardization of work procedures is high. Thus, it might be that communication about ideas is more beneficial under different working conditions.

\section{Study limitations and strengths}

One obvious limitation of our study is the small sample size, which does not allow for more sophisticated statistical analyses. Despite the small sample size, we were able to provide support for a part of our hypotheses. Taking into account that a small sample size makes it possible to detect only strong effects, attaches further value to our results. Aside from the small sample size, our specific sample might limit the generalizability of the results. Future research will need to replicate our findings, especially with samples where creativity is an expected part of the job.

Furthermore, the cross-sectional design of our study does not allow any causal interpretations to be drawn. For example, we tested whether idearelated communication is a predictor of engagement in the creative process. However, we cannot rule out that engagement in the creative process causes an individual to engage more in idea-related communication. Future studies should therefore use longitudinal or experimental designs to address causality.

With regard to our assessment of the creative process, we relied on participants' retrospective self-ratings, which may be biased. In addition, engagement in the creative process might not always be conscious and therefore participants might not have been able to provide accurate selfreports. We tried to minimize this problem by limiting the time of retrospectively reported ideas to the previous month and by asking specific questions that could further be explained or prompted by the interviewer. The interviewer did not report any odd situations indicating that a participant faked an answer, and participants did not indicate any problems with the self-report procedure. However, biases due to the biased characteristics of human memory or due to the report of unconscious processes cannot be ruled out completely. Future research may examine the correspondence between self-reports and objective observations or real-time thinking aloud protocols during creative problem solving. 
Most important to note is that we used different methods at different times to collect data and thus minimized common method variance. We used questionnaire data as well as interview data that was partially coded by participants themselves and partially coded by expert raters (Bartholomew et al., 2000). Therefore, our predictor and criterion variables originate from three sources, reducing common method bias (Podsakoff et al., 2003).

\section{Implications for research and practice}

As we developed a new method of assessing the creative process, this method needs additional support for validity. Further studies with different samples and methods are necessary to replicate our findings and to examine whether the structure of the creativity subprocesses is invariant across occupations and tasks. Some authors proposed to distinguish between different types of creativity (Kaufmann, 2003; Unsworth, 2001), and they expected that the process can vary accordingly (Lubart, 2001; Unsworth, 2001).

In our study, we did not address the implementation of an idea. Implementing a creative idea makes it necessary to convince others, to find support, and to search for possibilities to push one's idea through. PI might also play an important role in this process (Miron, Erez, \& Naveh, 2004; Rank et al., 2004). Future research should therefore investigate the implementation of creative ideas considering PI as one factor that could predict successful implementation.

With regard to idea-related communication, research is needed that examines the function and process of communicating with others about an idea. Recent theories propose a multilevel model of creativity that takes into account that creativity occurs at different levels, that is, the individual, the team, and the organizational level (Drazin, Glynn, \& Kazanjian, 1999; Taggar, 2002). Idea-related communication could serve as the connector between these levels. By communicating with others about one's idea, creative problem solving might be raised to the team or organizational level or might stimulate others to work on the creative idea. It is also conceivable that the development of a creative idea switches from the individual to the team level and back to the individual level. Our study demonstrated the importance of idea communication for individual engagement in the creative process. Future research should examine the role of communication during the creative process at various organizational levels.

Our study also has implications for practice. Assuming a causal link from idea-related communication to the engagement in the creative process, one should foster idea-related communication to increase engagement in the different stages of the creative process. Organizations or supervisors can implement meetings to discuss "ideas in progress" or they can secure information channels for communicating with others. Possibilities for 
face-to-face contact, telephone, or e-mail provide employees with the opportunity to discuss their not yet fully developed ideas. A workplace arrangement that allows frequent and informal contact with others may be very useful to facilitate idea-related communication. Furthermore, supervisors can encourage communication by establishing a culture that values idea-related communication.

In addition, research on team climate and team innovation emphasized that team climate, particularly psychological safety (Edmondson, 1999) or participative safety (Anderson \& West, 1998), is important for communicating about ideas. Experiencing a climate of psychological safety means that individuals are not afraid of speaking up (Edmondson, 2003), and are willing and motivated to propose and discuss new ideas. Therefore, organizations and team leaders should foster a climate of psychological safety (cf. West \& Anderson, 1996).

PI turned out to be important in getting started in the creative process under external problem identification, and PI was positively related to idea creativity. Consequently, employees should be encouraged to show PI at work. An organization or a supervisor can establish working conditions that enhance PI, such as high job control or high task complexity (Frese \& Fay, 2001). Moreover, PI can be trained to a certain degree (Frese et al., 2002).

\section{CONCLUSION}

The idea that the creative process consists of different subprocesses has largely been ignored and, as far as we know, our study is the first that investigated these subprocesses and the relationship between these subprocesses and factors that are assumed to be important for creativity. To gain a better understanding of the creative process at work, it is promising to investigate its relationship with different personal or contextual factors. Research is needed to determine if and how various factors are related to the different stages and to the creative outcome. Now, creativity is demanded from researchers to develop and improve methods to assess the creative process order to broaden our view of how a creative idea is developed and pursued until it results in a creative outcome.

\section{REFERENCES}

Aiken, L. S., \& West, S. G. (1991). Multiple regression: Testing and interpreting interactions. Thousand Oaks, CA: Sage.

Amabile, T. M. (1988). A model of creativity and innovation in organizations. In B. M. Staw \& L. L. Cummings (Eds.), Research in organizational behavior (Vol. 10, pp. 123-167). Greenwich, CT: JAI Press.

Amabile, T. M. (1996). Creativity in context: Update to "The social psychology of creativity". Boulder, CO: Westview Press. 
Amabile, T. M., Mueller, J. S., Simpson, W. B., Hadley, C. N., Kramer, S. J., \& Fleming, L. (2002). Time pressure and creativity in organizations: A longitudinal field study (Working Paper). Boston: Harvard Business School.

Anderson, N. N. R., de Dreu, C. K. W., \& Nijstad, B. A. (2004). The routinization of innovation research: A constructively critical review of the state-of-the-science. Journal of Organizational Behavior, 25, 147-173.

Anderson, N. R., \& West, M. A. (1998). Measuring climate for work group innovation: Development and validation of the team climate inventory. Journal of Organizational Behavior, 19, 235-258.

Baron, R. M., \& Kenny, D. A. (1986). The moderator-mediator variable distinction in social psychological research: Conceptual, strategic, and statistical considerations. Journal of Personality and Social Psychology, 51, 1173-1182.

Bartholomew, K., Henderson, A. J. Z., \& Marcia, J. E. (2000). Coded semistructured interviews in social psychological research. In H. T. Reis \& C. M. Judd (Eds.), Handbook of research methods in social and personality psychology (pp. 286-312). Cambridge, UK: Cambridge University Press.

Brodbeck, F. C. (2001). Communication and performance in software development projects. European Journal of Work and Organizational Psychology, 10, 73-94.

Chi, M. T., de Leeuw, N., Chiu, M.-H., \& LaVancher, C. (1994). Eliciting self-explanations improves understanding. Cognitive Science, 18, 439-477.

Clayton, V. P., \& Birren, J. E. (1980). The development of wisdom across the life-span: A reexamination of an ancient topic. In P. B. Baltes \& U. Staudinger (Eds.), Life-span development and behavior (Vol. 3, pp. 103-135). New York: Academic Press.

Deci, E. L., \& Ryan, R. M. (1985a). The general causality orientations scale: Self-determination in personality. Journal of Research in Personality, 19, 109-134.

Deci, E. L., \& Ryan, R. M. (1985b). Intrinsic motivation and self-determination in human behavior. New York: Plenum.

Drazin, R., Glynn, M. A., \& Kazanjian, R. K. (1999). Multilevel theorizing about creativity in organizations: A sensemaking perspective. Academy of Management Review, 24, 286307.

Edmondson, A. (1999). Psychological safety and learning behavior in work teams. Administrative Science Quarterly, 44, 350-383.

Edmondson, A. C. (2003). Speaking up in the operating room: How team leaders promote learning in interdisciplinary action teams. Journal of Management Studies, 40, 1419-1452.

Ford, C. M. (1996). A theory of individual creative action in multiple social domains. Academy of Management Review, 21, 1112-1142.

Frese, M., \& Fay, D. (2001). Personal initiative: An active performance concept for work in the 21 st century. In B. M. Staw \& R. M. Sutton (Eds.), Research in organizational behavior (Vol. 23, pp. 133-187). Amsterdam: Elsevier Science.

Frese, M., Fay, D., Hilburger, T., Leng, K., \& Tag, A. (1997). The concept of personal initiative: Operationalization, reliability and validity of two German samples. Journal of Occupational and Organizational Psychology, 70, 139-161.

Frese, M., Garman, G., Garmeister, K., Halemba, K., Hortig, A., Pulwitt, T., et al. (2002). Training zur Erhöhung der Eigeninitiative bei Arbeitslosen: Bericht über einen Pilotversuch [Training to increase personal initiative of the unemployed: Report on a pilot study]. Zeitschrift für Arbeits- und Organisationspsychologie, 46, 89-97.

Frese, M., Kring, W., Soose, A., \& Zempel, J. (1996). Personal initiative at work: Differences between East and West Germany. Academy of Management Journal, 39, 37-63.

Frese, M., Teng, E., \& Wijnen, C. J. D. (1999). Helping to improve suggestion systems: Predictors of making suggestions in companies. Journal of Organizational Behavior, 20, $1139-1155$. 
Gilson, L. L., Mathieu, J. E., Shalley, C. E., \& Ruddy, T. M. (2005). Creativity and standardization: Complementary or conflicting drivers of team effectiveness? Academy of Management Journal, 48, 521-531.

Gilson, L. L., \& Shalley, C. E. (2004). A little creativity goes a long way: An examination of teams' engagement in creative processes. Journal of Management, 30, 453-470.

Hollenbeck, J. R., Williams, C. R., \& Klein, H. J. (1989). An empirical examination of the antecedents of commitment to difficult goals. Journal of Applied Psychology, 74, 18 -23.

Hyatt, D. E., \& Ruddy, T. M. (1997). An examination of the relationship between work group characteristics and performance: Once more into the breech. Personnel Psychology, 50, $553-585$.

Kaufmann, G. (2003). What to measure? A new look at the concept of creativity. Scandinavian Journal of Educational Research, 47, 235-251.

Keller, R. T. (2001). Cross-functional project groups in research and new product development: Diversity, communications, job stress, and outcomes. Academy of Management Journal, 44, $547-559$.

Leenders, R. T. A. J., van Englen, J. M. L., \& Kratzer, J. (2003). Virtuality, communication, and new product team creativity: A social network perspective. Journal of Engineering and Technology Management, 20, 69-92.

Lubart, T. I. (2001). Models of the creative process: Past, present and future. Creativity Research Journal, 13, 295-308.

Miron, E., Erez, M., \& Naveh, E. (2004). Do personal characteristics and cultural values that promote innovation, quality, and efficiency compete or complement each other? Journal of Organizational Behavior, 25, 175-199.

Mumford, M. D., Whetzel, D. L., \& Reiter-Palmon, R. (1997). Thinking creatively at work: Organization influences on creative problem solving. Journal of Creative Behavior, 31, 7-17.

Ohly, S., Sonnentag, S., \& Pluntke, F. (2006). Routinization and its relationship with creative and proactive outcomes. Journal of Organizational Behavior, 27, 257-279.

Oldham, G. R. (2003). Stimulating and supporting creativity in organizations. In S. E. Jackson, M. A. Hitt, \& A. S. DeNisi (Eds.), Managing knowledge for sustained competitive advantage. New York: Jossey-Bass.

Oldham, G. R., \& Cummings, A. (1996). Employee creativity: Personal and contextual factors at work. Academy of Management Journal, 39, 607-634.

Pallak, M. S., \& Sullivan, J. J. (1979). The effect of commitment, threat and restoration of freedom on attitude change and action-taking. Personality and Social Psychology Bulletin, 5, $307-310$.

Perry-Smith, J. E., \& Shalley, C. E. (2003). The social side of creativity: A static and dynamic social network perspective. Academy of Management Review, 28, 89-106.

Podsakoff, P. M., MacKenzie, S. B., Jeong-Yeon, L., \& Podsakoff, N. P. (2003). Common method biases in behavioral research: A critical review of the literature and recommended remedies. Journal of Applied Psychology, 88, 879-903.

Rank, J., Pace, V. L., \& Frese, M. (2004). Three avenues for future research on creativity, innovation, and initiative. Applied Psychology: An International Review, 53, 518-528.

Scott, S. G., \& Bruce, R. A. (1994). Determinants of innovative behavior: A path model of individual innovation in the workplace. Academy of Management Journal, 37, 580-607.

Shalley, C. E., Zhou, J., \& Oldham, G. R. (2004). The effects of personal and contextual characteristics on creativity: Where should we go from here? Journal of Management, 30, $933-958$.

Staudinger, U., \& Baltes, P. B. (1996). Interactive minds: A facilitative setting for wisdomrelated performance? Journal of Personality and Social Psychology, 71, 746-762.

Stein, M. I. (1953). Creativity and culture. Journal of Psychology: Interdisciplinary and Applied, $36,311-322$. 
Sternberg, R. J., O’Hara, L. A., \& Lubart, T. I. (1997). Creativity as investment. California Management Review, 40, 8-21.

Taggar, S. (2002). Individual creativity and group ability to utilize individual creative resources: A multilevel model. Academy of Management Journal, 45, 315-330.

Unsworth, K. L. (2001). Unpacking creativity. Academy of Management Review, 26, 289-297.

Unsworth, K. L., \& Parker, S. K. (2003). Proactivity and innovation: Promoting a new workforce for the new workplace. In D. Holman, T. Wall, C. W. Clegg, P. Sparrow, \& A. Howard (Eds.), The new workplace (pp. 175-196). Chichester, UK: Wiley.

Wallas, G. (1926). The art of thought. London: J. Cape.

West, M. A. (2002). Sparkling fountains or stagnant ponds: An integrative model of creativity and innovation implementation in work groups. Applied Psychology: An International Review, 51, 355-387.

West, M. A., \& Anderson, N. R. (1996). Innovation in top management teams. Journal of Applied Psychology, 81, 680-693.

Zhou, J. (1998). Feedback valence, feedback style, task autonomy, and achievement orientation: Interactive effects on creative performance. Journal of Applied Psychology, 83, 261-276.

Zhou, J. (2003). When the presence of creative coworkers is related to creativity: Role of supervisor close monitoring, developmental feedback, and creative personality. Journal of Applied Psychology, 88, 413-422.

Zhou, J., \& George, J. M. (2001). When job dissatisfaction leads to creativity: Encouraging the expression of voice. Academy of Management Journal, 44, 682-696.

Zhou, J., \& Oldham, G. R. (2001). Enhancing creative performance: Effects of expected developmental assessment strategies and creative personality. Journal of Creative Behavior, $35,151-167$.

Original manuscript received January 2006 Revised manuscript received September 2006 First published online 7 September 2007 